\title{
Clinical Manifestations of Portal Hypertension
}

\author{
Said A. Al-Busafi, ${ }^{1,2}$ Julia McNabb-Baltar, ${ }^{2}$ Amanda Farag, ${ }^{3}$ and Nir Hilzenrat ${ }^{4}$ \\ ${ }^{1}$ Department of Medicine, College of Medicine and Health Sciences, Sultan Qaboos University, P.O. Box 35, 123 Muscat, Oman \\ ${ }^{2}$ Department of Gastroenterology, Royal Victoria Hospital, McGill University Health Center, Montreal, QC, Canada H3A 1A1 \\ ${ }^{3}$ Department of Medicine, Royal Victoria Hospital, McGill University Health Center, Montreal, QC, Canada H3A 1A1 \\ ${ }^{4}$ Department of Gastroenterology, Jewish General Hospital, McGill University, Montreal, QC, Canada
}

Correspondence should be addressed to Said A. Al-Busafi, busafis@squ.edu.om

Received 27 February 2012; Revised 20 July 2012; Accepted 25 July 2012

Academic Editor: Averell Sherker

Copyright ( 12012 Said A. Al-Busafi et al. This is an open access article distributed under the Creative Commons Attribution License, which permits unrestricted use, distribution, and reproduction in any medium, provided the original work is properly cited.

\begin{abstract}
The portal hypertension is responsible for many of the manifestations of liver cirrhosis. Some of these complications are the direct consequences of portal hypertension, such as gastrointestinal bleeding from ruptured gastroesophageal varices and from portal hypertensive gastropathy and colopathy, ascites and hepatorenal syndrome, and hypersplenism. In other complications, portal hypertension plays a key role, although it is not the only pathophysiological factor in their development. These include spontaneous bacterial peritonitis, hepatic encephalopathy, cirrhotic cardiomyopathy, hepatopulmonary syndrome, and portopulmonary hypertension.
\end{abstract}

\section{Introduction}

Portal hypertension $(\mathrm{PH})$ is a common clinical syndrome defined as the elevation of hepatic venous pressure gradient (HVPG) above $5 \mathrm{~mm} \mathrm{Hg}$. PH is caused by a combination of two simultaneous occurring hemodynamic processes: (1) increased intrahepatic resistance to passage of blood flow through the liver due to cirrhosis and (2) increased splanchnic blood flow secondary to vasodilatation within the splanchnic vascular bed. PH can be due to many different causes at prehepatic, intrahepatic, and posthepatic sites (Table 1). Cirrhosis of the liver accounts for approximately $90 \%$ of cases of $\mathrm{PH}$ in Western countries.

The importance of $\mathrm{PH}$ is defined by the frequency and severity of its complications including variceal bleeding, spontaneous bacterial peritonitis, and hepatorenal syndrome, which represent the leading causes of death and of liver transplantation in patients with cirrhosis. $\mathrm{PH}$ is considered to be clinically significant when HVPG exceeds 10 to $12 \mathrm{~mm} \mathrm{Hg}$, since this is the threshold for the clinical complications of PH to appear [1]. Proper diagnosis and management of these complications are vital to improving quality of life and patients' survival. This paper will review the multisystemic manifestations of $\mathrm{PH}$ in cirrhosis.

\section{Gastrointestinal Manifestations}

2.1. Gastroesophageal (GE) Varices. Approximately $5-15 \%$ of cirrhotics per year develop varices, and it is estimated that the majority of patients with cirrhosis will develop GE varices over their lifetime. The presence of GE varices correlates with the severity of liver disease; while only $40 \%$ of child A patients have varices, they are present in $85 \%$ of child C patients (Table 2) [2].

Collaterals usually exist between the portal venous system and the systemic veins. The resistance in the portal vessels is normally lower than in the collateral circulation, and so blood flows from the systemic bed into the portal bed. However, when $\mathrm{PH}$ develops, the portal pressure is higher than systemic venous pressure, and this leads to reversal of flow in these collaterals. In addition, the collateral circulatory bed also develops through angiogenesis and the development of new blood vessels in an attempt to decompress the portal 
TABLE 1: Causes of portal hypertension (PH).

Prehepatic PH (normal wedged hepatic venous pressure (WHVP) and free hepatic venous pressure (FHVP) with normal hepatic venous pressure gradient (HVPG))

Portal vein thrombosis

Splenic vein thrombosis

Congestive splenomegaly (Banti's syndrome)

Arteriovenous fistula

Hepatic PH (increased WHVP, normal FHVP, and increased HVPG)

Presinusoidal

Schistosomiasis

Congenital hepatic fibrosis

Sinusoidal

Cirrhosis-many causes

Alcoholic hepatitis

Nodular regenerative hyperplasia

Polycystic liver disease

Postsinusoidal

Sinusoidal obstructive syndrome

Budd-Chiari syndrome

Posthepatic PH (increased WHVP and FHVP and normal HVPG)

Inferior vena cava webs, thrombosis

Cardiac causes (restrictive cardiomyopathy, constrictive pericarditis, and congestive heart failure)

Pulmonary hypertension

circulation [3]. The areas where major collaterals occur between the portal and systemic venous system are shown in Table 3. Unfortunately these collaterals are insufficient to decompress the $\mathrm{PH}$, leading to complications including variceal bleeding.

GE area is the main site of formation of varices [4]. Esophageal varices (EV) form when the HVPG exceeds $10 \mathrm{~mm} \mathrm{Hg}$ [5]. In the lower 2 to $3 \mathrm{~cm}$ of the esophagus, the varices in the submucosa are very superficial and thus have thinner wall. In addition, these varices do not communicate with the periesophageal veins and therefore cannot easily be decompressed. These are the reasons why EV bleeds only at this site.

Over the last decade, most practice guidelines recommend to screen known cirrhotics with endoscopy to look for GE varices. Varices should be suspected in all patients with stigmata of chronic liver disease such as spider nevi, jaundice, palmar erythema, splenomegaly, ascites, encephalopathy, and caput medusae. EV are graded as small $(<5 \mathrm{~mm})$ and large $(>5 \mathrm{~mm})$, where $5 \mathrm{~mm}$ is roughly the size of an open biopsy forceps [6].

The rate of progression of small EV to large is $8 \%$ per year [2]. Decompensated cirrhosis (child B or C), presence of red wale marks (defined as longitudinal dilated venules resembling whip marks on the variceal surface), and alcoholic cirrhosis at the time of baseline endoscopy are the main factors associated with the progression from small to large EV
TABLe 2: Child-Pugh-Turcotte (CPT) Classification of the Severity of Cirrhosis.

\begin{tabular}{lccc}
\hline Parameter & \multicolumn{3}{c}{ Points assigned } \\
& 1 & 2 & 3 \\
\hline Ascites & None & Mild/Moderate & Tense \\
Hepatic encephalopathy & None & Grade 1-2 & Grade 3-4 \\
Bilirubin micromol/L & $<34.2(<2)$ & $34.2-51.3(2-3)$ & $>51.3(>3)$ \\
(mg/dL) & $>35(>3.5)$ & $28-35(2.8-3.5)$ & $<28(<2.8)$ \\
Albumin g/L (g/dL) & $<4$ & $4-6$ & $>6$ \\
PT (Sec over control) or & $<1.7$ & $1.7-2.3$ & $>2.3$ \\
INR & & & \\
CPT classification & & & \\
$\quad$ Child A: $5-6$ points & & & \\
Child B: 7-9 points & & & \\
Child C: $10-15$ points & & & \\
\hline
\end{tabular}

[2]. EV bleeding occurs at a yearly rate of 5\%-15\% [7]. The predictors of first bleeding include the size of varices, severity of cirrhosis (Child B or C), variceal pressure $(>12 \mathrm{~mm} \mathrm{Hg})$, and the endoscopic presence of red wale marks $[7,8]$. Although EV bleeding stops spontaneously in up to $40 \%$ of patients, and despite improvements in therapy over the last decade, the 6 weeks mortality rate is still $\geq 20 \%$ [9].

Gastroesophageal varices (GOV) are an extension of EV and are categorized based on Sarin's classification into 2 types (Figure 1). The most common are Type 1 (GOV1) varices, which extend along the lesser curvature. Type $2 \mathrm{GOV}$ (GOV2) are those that extend along the fundus. They are longer and more tortuous than GOV1. Isolated gastric varices (IGV) occur in the absence of EV and are also classified into 2 types. Type 1 (IGV1) are located in the fundus and tend to be tortuous and complex, and type 2 (IVG2) are located in the body, antrum, or around the pylorus. When IGV1 is present, one must exclude splenic vein thrombosis. $\mathrm{GV}$ are less common than $\mathrm{EV}$ and are present in 5\%-30\% of patients with $\mathrm{PH}$ with a reported incidence of bleeding of about $25 \%$ in 2 years, with a higher bleeding incidence for fundal varices [10]. Predictors of GV bleeding include the size of fundal varices (large $(>10 \mathrm{~mm})>$ medium $(5-10 \mathrm{~mm})$ $>$ small $(<5 \mathrm{~mm})$ ), severity of cirrhosis (child class $C>B>A$ ), and endoscopic presence of variceal red spots (defined as localized reddish mucosal area or spots on the mucosal surface of a varix) [11].

2.2. Ectopic Varices $(E c V)$. EcV are best defined as large portosystemic venous collaterals occurring anywhere in the abdomen except for the GE region [12]. They are an unusual cause of GI bleeding, but account for up to $5 \%$ of all variceal bleeding [13]. Compared to GE varices, EcV are difficult to locate, occur at distal sites, and when identified, the choice of therapy is unclear, therefore representing a clinical challenge [12]. Furthermore, bleeding EcV may be associated with poor prognosis, with one study quoting mortality reaching $40 \%$ [14]. Different areas of EcV are the duodenum, 
TABLE 3: Location and blood vessels of collaterals between the portal and systemic venous circulations.

\begin{tabular}{lcc}
\hline Location & Postal circulation & Systemic circulation \\
\hline Gastroesophageal junction & Short gastric and left gastric (coronary) veins & Azygos vein \\
Rectum & Superior hemorrhoidal veins & Middle and inferior hemorrhoidal veins \\
Umbilical (caput medusa) & Left portal via a recannulated umbilical vein & Epigastric venous plexus of the abdominal wall \\
Retroperitoneum & Mesentric veins & Intercostal, phrenic, lumbar, and renal veins \\
\hline
\end{tabular}

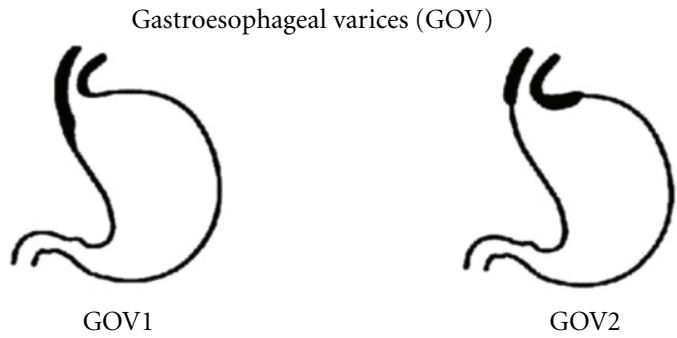

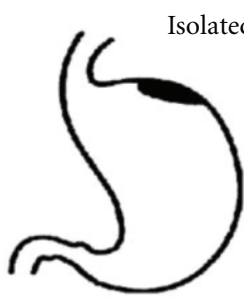

IGV1 (a)

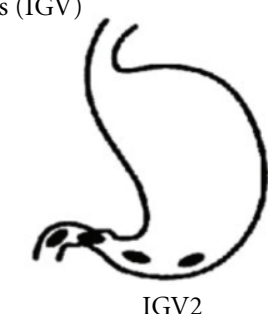

(b) jejunum, ileum, colon, rectum, peristomal, biliary tree, gallbladder, peritoneum, umbilicus, bare area of the liver, ovary, vagina, and testis $[15,16]$.

The prevalence of EcV varies in the literature and seems to be related to the etiology of the $\mathrm{PH}$ and the diagnostic modalities used [17]. In patients with $\mathrm{PH}$ due to cirrhosis, duodenal varices are seen in $40 \%$ of patients undergoing angiography [18]. Results of a survey for EcV conducted over 5 years in Japan identified 57 cases of duodenal varices; they were located in the duodenal bulb in 3.5\%, the descending part in $82.5 \%$, and the transverse part in $14.0 \%$ [15].

In contrast to duodenal varices, it appears that most cases of varices in other portions of the small bowel and colonic varices are seen in patients with cirrhosis who have previously undergone abdominal surgery [12]. Using advanced endoscopic technologies, particularly capsule endoscopy and enteroscopy, the prevalence of small bowel varices is estimated to be approximately $69 \%$ in patients with $\mathrm{PH}$ [19]. The prevalence of colonic varices and rectal varices has been found to be $34 \%$ to $46 \%[20,21]$ and $10 \%$ to $40 \%$ [22], respectively, in patients with cirrhosis undergoing colonoscopy. It is important to differentiate rectal varices from hemorrhoids; rectal varices extend more than $4 \mathrm{~cm}$ above the anal verge, are dark blue in color, collapse with digital pressure, and do not prolapse into the proctoscope on examination, whereas hemorrhoids do not extend proximal to the dentate line, are purple in color, do not collapse with digital pressure, and often prolapse into the proctoscope [22, 23]. Stomal varices are a particularly common cause of EcV and can occur in patients with cirrhosis secondary to primary sclerosing cholangitis (PSC) [12].

In the west, because the prevalence of noncirrhotic $\mathrm{PH}$ is low, most bleeding EcV is usually associated with cirrhotic $\mathrm{PH}(6,8)$. Although EcV can occur at several sites, bleeding $\mathrm{EcV}$ are most commonly found in the duodenum and at sites of previous bowel surgery including stomas.

In a review of 169 cases of bleeding $\mathrm{EcV}, 17 \%$ occurred in the duodenum, $17 \%$ in the jejunum or ileum, $14 \%$ in the colon, $8 \%$ in the rectum, and $9 \%$ in the peritoneum. In the review, 26\% bled from stomal varices and a few from infrequent sites such as the ovary and vagina [24].

Portal biliopathy, which includes abnormalities (stricture and dilatation) of both extra and intrahepatic bile ducts and varices of the gallbladder, is associated with $\mathrm{PH}$, particularly extrahepatic portal vein obstruction $[25,26]$. They are also seen associated with cirrhosis, non-cirrhotic portal fibrosis, and congenital hepatic fibrosis [27]. While a majority of these patients are asymptomatic, some present with a raised alkaline phosphatase level, abdominal pain, fever, and cholangitis. Choledocholithiasis may develop as a complication and manifest as obstructive jaundice with or without cholangitis [26]. On cholangiography, bile-duct varices may be visualized as multiple, smooth, mural-filling defects with narrowing and irregularity resulting from compression of the portal vein and collateral vessels. They may mimic PSC or cholangiocarcinoma (pseudocholangiocarcinoma sign) [28].

2.3. Portal Hypertensive Intestinal Vasculopathies. Mucosal changes in the stomach in patients with $\mathrm{PH}$ include portal hypertensive gastropathy $(\mathrm{PHG})$ and gastric vascular ectasia. PHG describes the endoscopicappearance of gastric mucosa with a characteristic mosaic, or snake-skin-like appearance with or without red spots. It is a common finding in patients with $\mathrm{PH}$ [29]. The prevalence of PHG parallels the severity of $\mathrm{PH}$ and it is considered mild when only a mosaic-like pattern is present and severe when superimposed discrete red spots are also seen. Bleeding (acute or chronic) from these lesions is relatively uncommon, and rarely severe [30]. Patients with chronic bleeding usually present with chronic iron deficiency anemia.

In gastric vascular ectasia, collection of ectatic vessels can be seen on endoscopy as red spots without a mosaiclike pattern [31]. When the aggregates are confined to the antrum of the stomach, the term gastric antral vascular ectasia (GAVE) is used, and if aggregates in the antrum are 
linear, the term watermelon stomach is used to describe the lesion. The prevalence of GAVE syndrome in cirrhosis is low [32] and can be endoscopically difficult to differentiate from severe PHG. Therefore, gastric biopsy may be required to differentiate them as histologically GAVE lesions are completely distinct from PHG (Table 4) [33].

Small bowel might also show mucosal changes related to $\mathrm{PH}$, which is called portal hypertensive enteropathy (PHE). The diagnosis of PHE has been limited in the past due to the difficult access to the small bowel. With advanced endoscopic techniques such as capsule endoscopy and enteroscopy, PHE is now thought to be a frequent finding in patients with cirrhosis, perhaps as common as PHG, and may cause occult GI blood loss [34, 35].

Portal hypertensive colopathy (PHC) refers to mucosal edema, erythema, granularity, friability, and vascular lesions of the colon in PH. PHC may be confused with colitis [36, 37]. Although they are found in up to $70 \%$ of patients with $\mathrm{PH}$ and are more common in patients with EV and PHG, they rarely cause bleeding $[38,39]$.

\subsection{Ascites and Spontaneous Bacterial Peritonitis (SBP).} Ascites is defined as the accumulation of free fluid in the peritoneal cavity. Cirrhotic $\mathrm{PH}$ is the most common cause of ascites, which accounts for approximately $75 \%$ patients with ascites. About $60 \%$ of patients with cirrhosis develop ascites during 10 years of observation [40]. The development of ascites is an important event in cirrhosis as the mortality is approximately $50 \%$ at 2 years without a liver transplantation [41]. The formation of ascites in cirrhosis is due to a combination of abnormalities in both renal function and portal and splanchnic circulation. The main pathogenic factor is sodium retention [42].

The main clinical symptom of patients with ascites is an increase in abdominal girth, often accompanied by lowerlimb edema. In some cases, the accumulation of fluid is so severe that respiratory function and physical activity is impaired. In most cases, ascites develop insidiously over the course of several weeks. Patients must have approximately $1500 \mathrm{~mL}$ of fluid for ascites to be detected reliably by physical examination. Dyspnea in these patients can occur as a consequence of increasing abdominal distension and/or accompanying pleural effusions. Increased intra-abdominal pressure might favour the development of abdominal hernias (mainly umbilical) in patients with cirrhosis and longstanding ascites [43].

The current classification of ascites, as defined by the International Ascites Club, divides patients in three groups (Table 5) [44]. Patients with refractory ascites are those that do not respond to sodium restriction and high doses of diuretics or develop diuretic-induced side effects that preclude their use.

Ascites may not be clinically detectable when present in small volumes. In larger volumes, the classic findings of ascites are adistended abdomen with a fluid thrill or shifting dullness. Ascites must be differentiated from abdominal distension due to other causes such as obesity, pregnancy, gaseous distension of bowel, bladder distension, cysts, and
TABLE 4: Comparison of portal hypertensive gastropathy (PHG) and gastric antral vascular ectasia (GAVE).

\begin{tabular}{|c|c|c|}
\hline FEATURE & PHG & GAVE \\
\hline Relation with $\mathrm{PH}$ & Causal & Coincidental \\
\hline Distribution in stomach & Mainly proximal & Mainly distal \\
\hline Mosaic pattern & Present & Absent \\
\hline Red color signs & Present & Present \\
\hline \multicolumn{3}{|l|}{ Pathology } \\
\hline Thrombi & - & +++ \\
\hline Spindle cell proliferation & + & ++ \\
\hline Fibrohyalinosis & - & +++ \\
\hline Treatment & $\begin{array}{l}\beta \text {-adrenergic } \\
\text { blockers } \\
\text { TIPS/shunt } \\
\text { surgery }\end{array}$ & $\begin{array}{c}\text { Endoscopic } \\
\text { Antrectomy and } \\
\text { Billroth I } \\
\text { Liver transplantation }\end{array}$ \\
\hline
\end{tabular}

PH: portal hypertension, TIPS: transjugular intrahepatic portosystemic shunt.

TABLE 5: International ascites club grading system for ascites.

\begin{tabular}{|c|c|}
\hline Grade of ascites & Definition \\
\hline Grade 1 ascites & Mild ascites only detectable by ultrasound \\
\hline Grade 2 ascites & $\begin{array}{l}\text { Moderate ascites evident by moderate } \\
\text { symmetrical distension of abdomen }\end{array}$ \\
\hline Grade 3 ascites & $\begin{array}{l}\text { Large or gross ascites with marked abdominal } \\
\text { distension }\end{array}$ \\
\hline
\end{tabular}

tumours. Ultrasonography is used to confirm the presence of minimal ascites and guide diagnostic paracentesis.

Successful treatment depends on an accurate diagnosis of the cause of ascites. Paracentesis with analysis of ascitic fluid is the most rapid and cost-effective method of diagnosis. It should be done in patients with ascites of recent onset, cirrhotic patients with ascites admitted to hospital, or those with clinical deterioration. The most important analyses are cell count, fluid culture, and calculation of the serum: ascites albumin gradient (SAAG), which reflects differences in oncotic pressures and correlates with portal venous pressure. It SAAG is greater or equal to $1.1 \mathrm{~g} / \mathrm{dL}$ ( or $11 \mathrm{~g} / \mathrm{L}$ ), ascites is ascribed to $\mathrm{PH}$ with approximately $97 \%$ accuracy [45].

Patients with cirrhosis and ascites are also at risk of developing infections, particularly spontaneous bacterial peritonitis (SBP). SBP occurs in approximately $10 \%$ of hospitalized cirrhotic patients [46], with an associated mortality of $20-40 \%$ if untreated [47]. Many patients are asymptomatic, but clinical signs can include abdominal pain, fever, and diarrhea. The diagnosis of SBP is based on neutrophil count $>250$ cells $/ \mathrm{mm}^{3}$ in the ascitic fluid.

\section{Renal Manifestations}

3.1. Hepatorenal Syndrome. Hepatorenal syndrome (HRS) is a common complication seen in patients with advanced cirrhosis and $\mathrm{PH}$ [48]. HRS can also be seen in other types 
TABLE 6: Revised diagnostic criteria of Hepatorenal syndrome.

(i) Chronic or acute liver disease with advanced liver failure and portal hypertension

(ii) Plasma creatinine concentration $>1.5 \mathrm{mg} / \mathrm{dL}$ (133 micromol/L)

(iii) The absence of other apparent cause: shock, ongoing bacterial infection, volume depletion, current or recent use of nephrotoxic drugs

(iv) Lack of improvement in renal function after volume expansion with intravenous albumin $(1 \mathrm{~g} / \mathrm{kg}$ of body weight per day up to $100 \mathrm{~g} /$ day) for at least two days and withdrawal of diuretics

(v) Absence of parenchymal kidney disease as indicated by proteinuria $>500 \mathrm{mg} /$ day, microhematuria ( $>50$ red blood cells per high power field) or ultrasonographic evidence of obstructive uropathy or renal parenchymal disease

of severe chronic liver disease, alcoholic hepatitis, or in acute liver failure. This syndrome generally predicts poor prognosis [48]. HRS has been defined in the literature as a reversible functional renal impairment in the absence of other causes of renal failure, tubular dysfunction, proteinuria, or morphological alterations in histological studies. Precise and accurate diagnostic criteria have been established in order to clearly define this syndrome (Table 6) [49]. The diagnosis remains one of exclusion.

The reported incidence of HRS is approximately $10 \%$ among hospitalized patients with cirrhosis and ascites. The probability of occurrence of HRS in patients with cirrhosis is around $20 \%$ after 1 year and $40 \%$ after 5 years [50]. The pathogenesis of HRS is not completely understood, but is likely the result of an extreme underfilling of the peripheral arterial circulation secondary to arterial vasodilatation in the splanchnic circulation [51]. In addition, recent data indicates that a reduction in cardiac output also plays a significant role [52].

HRS-associated renal failure is seen in late stages of cirrhosis and is marked by severe oliguria, increased sodium and water retention, volume overload, hyperkalemia, and spontaneous dilutional hyponatremia. There are two main subtypes of HRS described [49]. Type 1 HRS is a rapidly progressive renal failure that is defined by doubling of serum creatinine $>2.5 \mathrm{mg} / \mathrm{dL}(>221 \mu \mathrm{moL} / \mathrm{L})$ or a decrease of $50 \%$ in creatinine clearance $(<20 \mathrm{~mL} / \mathrm{min})$ in less than 2 weeks. This form of HRS is usually precipitated by gastrointestinal bleeds, large volume paracenthesis, acute alcoholic hepatitis and SBP [53]. In addition to renal failure, patients with type 1 HRS present deterioration in the function of other organs, including the heart, brain, liver, and adrenal glands. The median survival of these patients without treatment is $<2$ weeks, and almost all of them die within 10 weeks after onset of HRS. Type $2 \mathrm{HRS}$ is a moderate and stable renal failure with a serum creatinine of $>1.5 \mathrm{mg} / \mathrm{dL}(>133 \mu \mathrm{moL} / \mathrm{L})$ that remains stable over a longer period and is characterized by diuretics resistant ascites $[49,54]$.

\section{Neurological Manifestations}

4.1. Hepatic Encephalopathy. Hepatic encephalopathy (HE) is defined as neurologic and psychiatric dysfunction in a patient with chronic liver disease. The exact mechanism leading to this dysfunction is still poorly understood, but multiple factors appear to play a role in its genesis. The liver normally metabolizes ammonia, produced by enteric bacteria [56] and enterocytes $[57,58]$. In a patient with $\mathrm{PH}$, ammonia bypasses the liver through portosystemic shunt and reaches the astrocytes in the brain. Within the astrocyte, ammonia is metabolized into glutamine, which acts as an osmole to attract water, thus causing cerebral edema. In addition, direct ammonia toxicity triggers nitrosative and oxidative stress, which lead to astrocyte mitochondrial dysfunction $[59,60]$. Another important factor is the enhancement of gamma-aminobutyric acid (GABA-A) receptors through neuroinhibitory steroids (i.e., allopregnanolone) [61] and benzodiazepine. Benzodiazepine also contributes to astrocyte swelling through a specific receptor [62]. Finally, tryptophane byproducts indole and oxindole [63], manganese [64], inflammation, hyponatremia [65], and reduced acetylcholine through acetylcholinesterase activity [66] also contribute to cerebral dysfunction.

The clinical manifestations of HE can be subtle. Minimal hepatic encephalopathy (grade 0) (Table 7) can present with impaired driving ability [67], minimally impaired psychometric tests, decreased global functioning, and increased risk of falls [68]. In overt hepatic encephalopathy, diurnal sleep pattern changes will often precede neurologic symptoms. To add to the complexity, HE can be intermittent or persistent.

The severity of presentation is usually classified using the West Haven criteria (Table 7). Grade 1 hepatic encephalopathy represents lack of awareness, anxiety or euphoria, and short attention span. Change of personality, lethargy, and inappropriate behavior can be seen in grade 2 encephalopathy. More advanced features include disorientation, stupor, confusion (grade 3), and can even reach coma (grade 4). Focal neurologic symptoms, including hemiplegia, may also be observed [69]. Physical examination may be normal, but typical signs include bradykinesia, asterixis, hyperactive deep tendon reflexes and even decerebrate posturing [55].

\section{Pulmonary Manifestations}

5.1. Hepatopulmonary Syndrome. Hepatopulmonary syndrome (HPS) is a triad of liver disease, pulmonary vascular ectasia and impaired oxygenation. HPS is defined in the literature as a widened alveolar-arterial oxygen difference (A-a gradient) in room air $(>15 \mathrm{~mm} \mathrm{Hg}$ or $>20 \mathrm{~mm} \mathrm{Hg}$ in patients $>64$ years of age) with or without hypoxemia due to intrapulmonary vasodilatation in the presence of hepatic dysfunction $[70,71]$. This syndrome occurs mostly in those with $\mathrm{PH}$ (with or without cirrhosis) and indicates poor prognosis and higher mortality. Estimates of the prevalence of HPS among patients with chronic liver disease range from 4 to $47 \%$, depending upon the diagnostic criteria and methods used [71-73]. 
TABLE 7: West Haven Criteria of Severity of Hepatic Encephalopathy (Adapted with permission [55]).

\begin{tabular}{ll}
\hline & Trivial lack of awareness \\
Grade 1 & $\begin{array}{l}\text { Euphoria or anxiety } \\
\text { Shortened attention span } \\
\text { Impaired performance of addition }\end{array}$ \\
\hline & Lethargy or apathy \\
& Minimal disorientation for time and place \\
Grade 2 & $\begin{array}{l}\text { Subtle personality change } \\
\text { Inappropriate behavior }\end{array}$ \\
& Impaired performance of subtraction \\
\hline & Somnolence to semistupor, but responsive to \\
Grade 3 & Conful stimuli \\
& Gross disorientation \\
\hline Grade 4 & Coma (unresponsive to verbal or noxious stimuli) \\
\hline
\end{tabular}

HPS results in hypoxemia through pulmonary microvascular vasodilatation and intrapulmonary arteriovenous shunting resulting in ventilation-perfusion mismatch [74], and can occur even with mild liver disease [75]. Clinically, patients with HPS complain of progressive dyspnea on exertion, at rest, or both. Severe hypoxemia $\left(\mathrm{PaO}_{2}<60 \mathrm{~mm} \mathrm{Hg}\right)$ is often seen and strongly suggests HPS [70, 71]. A classical finding in HPS is orthodeoxia defined as a decreased arterial oxygen tension by more than $4 \mathrm{~mm} \mathrm{Hg}$ or arterial oxyhemoglobin desaturation by more than $5 \%$ with changing position from supine to standing. It is associated with platypnea defined as dyspnea worsened by upright position $[70,71]$. Platypnea-orthodeoxia is caused by the worsening of diffusion-perfusion matching and increased shunting at the lung bases in the upright position. There are no hallmark signs on physical exam; however, cyanosis, clubbing, and cutaneous telangiectasia (spider nevi) are commonly noted. Furthermore, systemic arterioembolisation may cause stroke, cerebral hemorrhage, or brain abscess, and can present with neurological deficits.

5.2. Portopulmonary Hypertension. Portopulmonary hypertension (PPH), a well-recognized complication of chronic liver disease, refers to pulmonary arterial hypertension (PAH) associated with $\mathrm{PH}$ when no alternative causes exist. It is defined by the presence of elevated pulmonary arterial pressure (mean pressure $>25 \mathrm{~mm} \mathrm{Hg}$ at rest and $30 \mathrm{~mm} \mathrm{Hg}$ on exertion) elevated pulmonary vascular resistance ( $>240$ dyne $\mathrm{s}^{-1} \mathrm{~cm}^{-5}$ ) in the presence of a pulmonary capillary wedge pressure $<15 \mathrm{~mm} \mathrm{Hg}$ [76].

The prevalence of $\mathrm{PPH}$ depends on the patient population studies and severity of the liver disease, $0.7-2 \%$ and $3.5-$ $16.1 \%$ in cirrhotics and patients undergoing liver transplantation, respectively. The development of PPH is independent of the cause of $\mathrm{PH}$, and it is often seen in cirrhosis. It is however, also described in those with $\mathrm{PH}$ due to nonhepatic pathologies such as portal venous thrombosis [71, 77]. $\mathrm{PH}$ seems to be the driving force of $\mathrm{PAH}$. The pathogenesis of $\mathrm{PPH}$ is not completely understood; however, several theories have been offered. The most widely accepted theory is that a humoral vasoactive substances (e.g., serotonin, endothelin1, interleukin-1, thromboxane B2, and secretin), normally metabolized by the liver, is able to reach the pulmonary circulation via portosystemic shunts, resulting in $\mathrm{PPH}[71$, 78, 79].

Clinically, most patients with $\mathrm{PPH}$ present with evidence of both $\mathrm{PAH}$ and $\mathrm{PH}$. Typically manifestations of $\mathrm{PH}$ precede those of PAH. The most common presenting symptom is progressive dyspnea on exertion [80] and less frequently fatigue, palpitations, syncope, hemoptysis, orthopnea, and chest pain. On physical exam, classical features include edema, an accentuated P2 and a systolic murmur, indicating tricuspid regurgitation $[71,77,80]$. In severe cases, signs and symptoms of right-heart failure can be noted.

5.3. Hepatic Hydrothorax. Hepatic hydrothorax is an uncommon complication of end-stage liver disease. It is defined as a pleural effusion greater than $500 \mathrm{~mL}$ in patients with cirrhosis in absence of primary cardiac, pulmonary, or pleural disease [81]. The underlying pathogenesis of hepatic hydrothorax is incompletely understood. Patients with cirrhosis and $\mathrm{PH}$ have abnormal extracellular fluid volume regulation resulting in passage of ascites from the peritoneal space to the pleural cavity via diaphragmatic defects generally in the tendinous portion of the diaphragm [82]. Negative intrathoracic pressure during inspiration pulls the fluid from the intra-abdominal cavity into the pleural cavity. Hydrothorax develops when the pleural absorptive capacity is surpassed, leading to accumulation of fluid in the pleural space. Multiple studies have shown the passage of fluid from the intra-abdominal space to the pleural space via $99 \mathrm{mTc}$ human albumin or $99 \mathrm{mTc}$-sulphur colloid [81].

Clinical manifestations of hepatic hydrothorax include shortness of breath, cough, hypoxemia, and chest discomfort [81]. Ascites may not always be present. Hepatic hydrothorax should always be suspected in patients with cirrhosis or $\mathrm{PH}$ and undiagnosed pleural effusion, regardless of the presence of ascites. Serious complications include acute tension hydrothorax with dyspnoea and hypotension [83] and spontaneous bacterial empyema [84].

\section{Other Organs Manifestations}

6.1. Cirrhotic Cardiomyopathy. Cirrhotic cardiomyopathy is defined as a chronic cardiac dysfunction in patients with cirrhosis. It occurs in up to $50 \%$ of patients with advanced cirrhosis. It is characterized by impaired contractile response and/or altered diastolic relaxation in the absence of other cardiac diseases. The pathophysiology of this condition is complex, and seemingly related to $\mathrm{PH}$ and cirrhosis. In advanced liver disease, splanchnic vasodilatation leads to a resting hyperdynamic state [85]. Plasma volume expands, leading to a relative central volume decrease [86]. In cirrhosis, the arterial vessel wall thickness and tone decreases, leading to reduced arterial compliance $[87,88]$. Autonomic dysfunction may also contribute to blunted cardiac response [89]. Ultimately, these factors lead to systolic and diastolic dysfunction. 
Symptoms associated with cirrhotic cardiomyopathy include dyspnea with exertion, impaired exercise capacity, paroxysmal nocturnal dyspnea, peripheral edema, and orthopnea. Less-frequent presentations include long QT on electrocardiography, arrhythmia, and sudden death [90].

6.2. Hepatic Osteodystrophy. Hepatic osteodystrophy is defined as bone disease (osteomalacia, osteoporosis, and osteopenia) associated with liver disease. Osteomalacia and osteoporosis are frequently seen in cirrhotic patients and can predispose to pathologic fractures. The pathophysiology of osteoporosis in liver disease is relatively complex. The leading hypothesis suggests that it is related to the uncoupling of osteoblastic and osteoclastic activity. Osteoclastogenic proinflammatory cytokines (interleukin $1(\mathrm{Il}-1)$ and tumor necrosis factor $\alpha(\mathrm{TNF} \alpha)$ ) are increased in hepatic fibrosis. Moreover, TNF $\alpha$ is increased in a rat model of $\mathrm{PH}$ [91]. Decreased osteoblastic activity has also been linked with insulin-like growth factor 1 in a rat model (IGF-1). Increasing IGF-1 levels are associated with liver disease severity [92]. Finally, vitamin $\mathrm{K}$ mediates the carboxylation of glutamyl residues on osteocalcin, stimulating osteoclastic activity [93].

Patients with osteoporosis are usually asymptomatic. They may present with pain following a nontraumatic fracture of the axial skeleton or bone deformity, including pronounced cervical kyphosis. Osteomalacia presentation is similar and includes proximal muscle weakness [94].

6.3. Hypersplenism. Hypersplenism is a common complication of massive congestive splenomegaly in patients with cirrhosis and $\mathrm{PH}$. In this condition, splenomegaly is associated with thrombocytopenia, leucopenia, or anemia or a combination of any the three $[95,96]$. Severe hypersplenism is present in about $1 / 3$ of patients with cirrhosis being assessed for liver transplantation. Most patients have no symptoms related to hypersplenism, however severe thrombocytopenia may increase the risk of bleeding, especially after invasive procedures.

\section{Conclusion}

Portal hypertension secondary to cirrhosis has multisystem effects and complications. Once a patient develops such complications, they are considered to have decompensated disease with the high morbidity and mortality. The quality of life and survival of patients with cirrhosis can be improved by the prevention and treatment of these complications.

\section{References}

[1] R. J. Groszmann, G. Garcia-Tsao, J. Bosch et al., "Beta-blockers to prevent gastroesophageal varices in patients with cirrhosis," New England Journal of Medicine, vol. 353, no. 21, pp. 22542261, 2005.

[2] M. Merli, G. Nicolini, S. Angeloni et al., "Incidence and natural history of small esophageal varices in cirrhotic patients," Journal of Hepatology, vol. 38, no. 3, pp. 266-272, 2003.
[3] L. T. Sumanovski, E. Battegay, M. Stumm, M. Van Der Kooij, and C. C. Sieber, "Increased angiogenesis in portal hypertensive rats: role of nitric oxide," Hepatology, vol. 29, no. 4, pp. 1044-1049, 1999.

[4] A. Vianna, P. C. Hayes, G. Moscoso et al., "Normal venous circulation of the gastroesophageal junction: a route to understanding varices," Gastroenterology, vol. 93, no. 4, pp. 876-889, 1987.

[5] G. Garcia-Tsao, R. J. Groszmann, and R. L. Fisher, "Portal pressure, presence of gastroesophageal varices and variceal bleeding," Hepatology, vol. 5, no. 3, pp. 419-424, 1985.

[6] R. de Franchis, J. P. Pascal, E. Ancona et al., "Definitions, methodology and therapeutic strategies in portal hypertension. A Consensus Development Workshop, Baveno, Lake Maggiore, Italy, April 5 and 6, 1990," Journal of Hepatology, vol. 15, no. 1-2, pp. 256-261, 1992.

[7] E. Brocchi, G. Caletti, G. Brambilla et al., "Prediction of the first variceal hemorrhage in patients with cirrhosis of the liver and esophageal varices. A prospective multicenter study," New England Journal of Medicine, vol. 319, no. 15, pp. 983-989, 1988.

[8] F. Nevens, R. Bustami, I. Scheys, E. Lesaffre, and J. Fevery, "Variceal pressure is a factor predicting the risk of a first variceal bleeding: a prospective cohort study in cirrhotic patients," Hepatology, vol. 27, no. 1, pp. 15-19, 1998.

[9] G. D'Amico and R. De Franchis, "Upper digestive bleeding in cirrhosis. Post-therapeutic outcome and prognostic indicators," Hepatology, vol. 38, no. 3, pp. 599-612, 2003.

[10] S. K. Sarin, D. Lahoti, S. P. Saxena, N. S. Murthy, and U. K. Makwana, "Prevalence, classification and natural history of gastric varices: a long- term follow-up study in 568 portal hypertension patients," Hepatology, vol. 16, no. 6, pp. 13431349, 1992.

[11] T. Kim, H. Shijo, H. Kokawa et al., "Risk factors for hemorrhage from gastric fundal varices," Hepatology, vol. 25, no. 2, pp. 307-312, 1997.

[12] D. Lebrec and J. P. Benhamou, "Ectopic varices in portal hypertension," Clinics in Gastroenterology, vol. 14, no. 1, pp. 105-121, 1985.

[13] M. Kinkhabwala, A. Mousavi, S. Iyer, and R. Adamsons, "Bleeding ileal varicosity demonstrated by transhepatic portography," American Journal of Roentgenology, vol. 129, no. 3, pp. 514-516, 1977.

[14] F. Khouqeer, C. Morrow, and P. Jordan, "Duodenal varices as a cause of massive upper gastrointestinal bleeding," Surgery, vol. 102, no. 3, pp. 548-552, 1987.

[15] N. Watanabe, A. Toyonaga, S. Kojima et al., "Current status of ectopic varices in Japan: results of a survey by the Japan Society for Portal Hypertension," Hepatology Research, vol. 40, no. 8, pp. 763-776, 2010.

[16] M. Farid and M. A. ElHoda, "Anorectal varices endoscopic dilemma. Joint Euro-Asian Congress of Endoscopic Surgery," Surgical Endoscopy, pp. 445-877, 1997.

[17] M. A. Almadi, A. Almessabi, P. Wong, P. M. Ghali, and A. Barkun, "Ectopic varices," Gastrointestinal Endoscopy, vol. 74, no. 2, pp. 380-388, 2011.

[18] G. Stephan and R. Miething, "X-ray diagnosis of varicose duodenal changes in poratal hypertension," Radiologe, vol. 8, no. 3, pp. 90-95, 1968.

[19] P. Figueiredo, N. Almeida, C. Lerias et al., "Effect of portal hypertension in the small bowel: an endoscopic approach," Digestive Diseases and Sciences, vol. 53, no. 8, pp. 2144-2150, 2008. 
[20] U. C. Ghoshal, P. K. Biswas, G. Roy, B. B. Pal, K. Dhar, and P. K. Banerjee, "Colonic mucosal changes in portal hypertension.," Tropical Gastroenterology, vol. 22, no. 1, pp. 25-27, 2001.

[21] L. S. Chen, H. C. Lin, F. Y. Lee, M. C. Hou, and S. D. Lee, "Portal hypertensive colopathy in patients with cirrhosis," Scandinavian Journal of Gastroenterology, vol. 31, no. 5, pp. 490-494, 1996.

[22] S. W. Hosking, A. G. Johnson, H. L. Smart, and D. R. Triger, "Anorectal varices, haemorrhoids, and portal hypertension," The Lancet, vol. 1, no. 8634, pp. 349-352, 1989.

[23] S. Ganguly, S. K. Sarin, V. Bhatia, and D. Lahoti, "The prevalence and spectrum of colonic lesions in patients with cirrhotic and noncirrhotic portal hypertension," Hepatology, vol. 21, no. 5, pp. 1226-1231, 1995.

[24] I. D. Norton, J. C. Andrews, and P. S. Kamath, "Management of ectopic varices," Hepatology, vol. 28, no. 4, pp. 1154-1158, 1998.

[25] M. S. Khuroo, G. N. Yattoo, S. A. Zargar et al., "Biliary abnormalities associated with extrahepatic portal venous obstruction," Hepatology, vol. 17, no. 5, pp. 807-813, 1993.

[26] R. Chandra, D. Kapoor, A. Tharakan, A. Chaudhary, and S. K. Sarin, "Portal biliopathy," Journal of Gastroenterology and Hepatology, vol. 16, no. 10, pp. 1086-1092, 2001.

[27] S. K. Sarin, V. Bhatia, and A. K. Jain, "Choledocholithiasis associated with portal biliopathy in patients with extrahepatic portal vein obstruction: management with endoscopic sphincterotomy," Gastrointestinal Endoscopy, vol. 42, no. 2, pp. 178181, 1995.

[28] Y. Bayraktar, F. Balkanci, B. Kayhan, A. Ozenc, S. Arslan, and H. Telatar, "Bile duct varices or 'pseudo-cholangiocarcinoma sign' in portal hypertension due to cavernous transformation of the portal vein," American Journal of Gastroenterology, vol. 87, no. 12, pp. 1801-1809, 1992.

[29] M. Merli, G. Nicolini, S. Angeloni, F. Gentili, A. F. Attili, and O. Riggio, "The natural history of portal hypertensive gastropathy in patients with liver cirrhosis and mild portal hypertension," American Journal of Gastroenterology, vol. 99, no. 10, pp. 1959-1965, 2004.

[30] M. Primignani, L. Carpinelli, P. Preatoni et al., "Natural history of portal hypertensive gastropathy in patients with liver cirrhosis," Gastroenterology, vol. 119, no. 1, pp. 181-187, 2000.

[31] M. Jabbari, R. Cherry, and J. O. Lough, "Gastric antral vascular ectasia: the watermelon stomach," Gastroenterology, vol. 87, no. 5, pp. 1165-1170, 1984.

[32] E. M. Ward, M. Raimondo, B. G. Rosser, M. B. Wallace, and R. D. Dickson, "Prevalence and natural history of gastric antral vascular ectasia in patients undergoing orthotopic liver transplantation," Journal of Clinical Gastroenterology, vol. 38, no. 10, pp. 898-900, 2004

[33] J. L. Payen, P. Calès, J. J. Voigt et al., "Severe portal hypertensive gastropathy and antral vascular ectasia are distinct entities in patients with cirrhosis," Gastroenterology, vol. 108, no. 1, pp. 138-144, 1995.

[34] U. M. Abdelaal, E. Morita, S. Nouda et al., "Evaluation of portal hypertensive enteropathy by scoring with capsule endoscopy: is transient elastography of clinical impact?" Journal of Clinical Biochemistry and Nutrition, vol. 47, no. 1, pp. 37-44, 2010.

[35] V. Misra, S. P. Misra, M. Dwivedi, and S. C. Gupta, "Histomorphometric study of portal hypertensive enteropathy," American Journal of Clinical Pathology, vol. 108, no. 6, pp. 652-657, 1997.
[36] E. J. Bini, C. E. Lascarides, P. L. Micale, and E. H. Weinshel, "Mucosal abnormalities of the colon in patients with portal hypertension: an endoscopic study," Gastrointestinal Endoscopy, vol. 52, no. 4, pp. 511-516, 2000.

[37] V. Misra, S. P. Misra, M. Dwivedi, P. A. Singh, and V. Kumar, "Colonic mucosa in patients with portal hypertension," Journal of Gastroenterology and Hepatology, vol. 18, no. 3, pp. 302308, 2003.

[38] G. Bresci, G. Parisi, and A. Capria, "Clinical relevance of colonic lesions in cirrhotic patients with portal hypertension," Endoscopy, vol. 38, no. 8, pp. 830-835, 2006.

[39] S. P. Misra, M. Dwivedi, V. Misra, S. Dharmani, B. K. Kunwar, and J. S. Arora, "Colonic changes in patients with cirrhosis and in patients with extrahepatic portal vein obstruction," Endoscopy, vol. 37, no. 5, pp. 454-459, 2005.

[40] P. Gines, E. Quintero, and V. Arroyo, "Compensated cirrhosis: natural history and prognostic factors," Hepatology, vol. 7, no. 1, pp. 122-128, 1987.

[41] G. D'Amico, A. Morabito, and L. Pagliaro, "Survival and prognostic indicators in compensated and decompensated cirrhosis," Digestive Diseases and Sciences, vol. 31, no. 5, pp. 468-475, 1986.

[42] A. Cardenas and V. Arroyo, "Mechanisms of water and sodium retention in cirrhosis and the pathogenesis of ascites," Best Practice and Research, vol. 17, no. 4, pp. 607-622, 2003.

[43] J. Belghiti and F. Durand, "Abdominal wall hernias in the setting of cirrhosis," Seminars in Liver Disease, vol. 17, no. 3, pp. 219-226, 1997.

[44] K. P. Moore, F. Wong, P. Gines et al., "The management of ascites in cirrhosis: report on the consensus conference of The International Ascites Club," Hepatology, vol. 38, no. 1, pp. 258266, 2003.

[45] B. A. Runyon, A. A. Montano, E. A. Akriviadis, M. R. Antillon, M. A. Irving, and J. G. McHutchison, "The serumascites albumin gradient is superior to the exudate-transudate concept in the differential diagnosis of ascites," Annals of Internal Medicine, vol. 117, no. 3, pp. 215-220, 1992.

[46] J. B. Nousbaum, J. F. Cadranel, P. Nahon et al., "Diagnostic accuracy of the Multistix 8 SG reagent strip in diagnosis of spontaneous bacterial peritonitis," Hepatology, vol. 45, no. 5, pp. 1275-1281, 2007.

[47] P. Tandon and G. Garcia-Tsao, "Bacterial infections, sepsis, and multiorgan failure in cirrhosis," Seminars in Liver Disease, vol. 28, no. 1, pp. 26-42, 2008.

[48] P. Ginès, M. Guevara, V. Arroyo, and J. Rodés, "Hepatorenal syndrome," The Lancet, vol. 362, no. 9398, pp. 1819-1827, 2003.

[49] V. Arroyo, P. Ginès, A. L. Gerbes et al., "Definition and diagnostic criteria of refractory ascites and hepatorenal syndrome in cirrhosis," Hepatology, vol. 23, no. 1, pp. 164-176, 1996.

[50] A. Gines, A. Escorsell, P. Gines et al., "Incidence, predictive factors, and prognosis of the hepatorenal syndrome in cirrhosis with ascites," Gastroenterology, vol. 105, no. 1, pp. 229-236, 1993.

[51] P. Ginès, A. Torre, C. Terra, and M. Guevara, "Review article: pharmacological treatment of hepatorenal syndrome," Alimentary Pharmacology and Therapeutics, vol. 20, supplement 3, pp. 57-62, 2004.

[52] V. Arroyo, J. Fernandez, and P. Ginès, "Pathogenesis and treatment of hepatorenal syndrome," Seminars in Liver Disease, vol. 28, no. 1, pp. 81-95, 2008. 
[53] H. M. Wadei, M. L. Mai, N. Ahsan, and T. A. Gonwa, "Hepatorenal syndrome: pathophysiology and management.," Clinical Journal of the American Society of Nephrology, vol. 1, no. 5, pp. 1066-1079, 2006.

[54] F. Salerno, A. Gerbes, P. Ginès, F. Wong, and V. Arroyo, "Diagnosis, prevention and treatment of hepatorenal syndrome in cirrhosis," Postgraduate Medical Journal, vol. 84, no. 998, pp. 662-670, 2008.

[55] P. Ferenci, A. Lockwood, K. Mullen, R. Tarter, K. Weissenborn, and A. T. Blei, "Hepatic encephalopathy-definition, nomenclature, diagnosis, and quantification: final report of the Working Party at the 11th World Congresses of Gastroenterology, Vienna, 1998," Hepatology, vol. 35, no. 3, pp. 716-721, 2002.

[56] A. J. Vince and S. M. Burridge, "Ammonia production by intestinal bacteria: the effects of lactose, lactulose and glucose," Journal of Medical Microbiology, vol. 13, no. 2, pp. 177-191, 1980.

[57] F. L. Weber Jr and G. L. Veach, "The importance of the small intestine in gut ammonium production in the fasting dog," Gastroenterology, vol. 77, no. 2, pp. 235-240, 1979.

[58] M. Plauth, A. E. Roske, P. Romaniuk, E. Roth, R. Ziebig, and H. Lochs, "Post-feeding hyperammonaemia in patients with transjugular intrahepatic portosystemic shunt and liver cirrhosis: role of small intestinal ammonia release and route of nutrient administration," Gut, vol. 46, no. 6, pp. 849-855, 2000.

[59] D. Häussinger, G. Kircheis, R. Fischer, F. Schliess, and S. V. Dahl, "Hepatic encephalopathy in chronic liver disease: a clinical manifestation of astrocyte swelling and low-grade cerebral edema?" Journal of Hepatology, vol. 32, no. 6, pp. 1035-1038, 2000.

[60] R. Avallone, M. L. Zeneroli, I. Venturini et al., "Endogenous benzodiazepine-like compounds and diazepam binding inhibitor in serum of patients with liver cirrhosis with and without overt encephalopathy," Gut, vol. 42, no. 6, pp. 861867, 1998.

[61] S. Ahboucha, G. P. Layrargues, O. Mamer, and R. F. Butterworth, "Increased brain concentrations of a neuroinhibitory steroid in human hepatic encephalopathy [2]," Annals of Neurology, vol. 58, no. 1, pp. 169-170, 2005.

[62] K. D. Mullen, K. M. Szauter, and K. Kaminsky-Russ, “'Endogenous' benzodiazepine activity in body fluids of patients with hepatic encephalopathy," The Lancet, vol. 336, no. 8707, pp. 81-83, 1990.

[63] O. Riggio, G. Mannaioni, L. Ridola et al., "Peripheral and splanchnic indole and oxindole levels in cirrhotic patients: a study on the pathophysiology of hepatic encephalopathy," American Journal of Gastroenterology, vol. 105, no. 6, pp. 13741381, 2010.

[64] C. Rose, R. F. Butterworth, J. Zayed et al., "Manganese deposition in basal ganglia structures results from both portalsystemic shunting and liver dysfunction," Gastroenterology, vol. 117, no. 3, pp. 640-644, 1999.

[65] M. Guevara, M. E. Baccaro, A. Torre et al., "Hyponatremia is a risk factor of hepatic encephalopathy in patients with cirrhosis: a prospective study with time-dependent analysis," American Journal of Gastroenterology, vol. 104, no. 6, pp. 1382 1389, 2009.

[66] M. Mendez, M. Mendez-Lopez, L. Lopez, M. A. Aller, J. Arias, and J. L. Arias, "Acetylcholinesterase activity in an experimental rat model of Type C hepatic encephalopathy," Acta Histochemica, vol. 113, no. 3, pp. 358-362, 2011.
[67] J. S. Bajaj, K. Saeian, C. M. Schubert et al., "Minimal hepatic encephalopathy is associated with motor vehicle crashes: the reality beyond the driving test," Hepatology, vol. 50, no. 4, pp. 1175-1183, 2009.

[68] E. Román, J. Córdoba, M. Torrens et al., "Minimal hepatic encephalopathy is associated with falls," American Journal of Gastroenterology, vol. 106, no. 3, pp. 476-482, 2011.

[69] J. F. Cadranel, E. Lebiez, V. Di Martino et al., "Focal neurological signs in hepatic encephalopathy in cirrhotic patients: an underestimated entity?" American Journal of Gastroenterology, vol. 96, no. 2, pp. 515-518, 2001.

[70] Z. J. Zhang and C. Q. Yang, "Progress in investigating the pathogenesis of hepatopulmonary syndrome," Hepatobiliary and Pancreatic Diseases International, vol. 9, no. 4, pp. 355360, 2010.

[71] R. Rodríguez-Roisin and M. J. Krowka, "Hepatopulmonary syndrome-a liver-induced lung vascular disorder," New England Journal of Medicine, vol. 358, no. 22, pp. 2318-2387, 2008.

[72] M. J. Krowka and D. A. Cortese, "Hepatopulmonary syndrome: current concepts in diagnostic and therapeutic considerations," Chest, vol. 105, no. 5, pp. 1528-1537, 1994.

[73] M. R. Arguedas, H. Singh, D. K. Faulk, and M. B. Fallon, "Utility of pulse oximetry screening for hepatopulmonary syndrome," Clinical Gastroenterology and Hepatology, vol. 5, no. 6, pp. 749-e1, 2007.

[74] P. D. King, R. Rumbaut, and C. Sanchez, "Pulmonary manifestations of chronic liver disease," Digestive Diseases, vol. 14, no. 2, pp. 73-82, 1996.

[75] G. A. Abrams, C. C. Jaffe, P. B. Hoffer, H. J. Binder, and M. B. Fallon, "Diagnostic utility of contrast echocardiography and lung perfusion scan in patients with hepatopulmonary syndrome," Gastroenterology, vol. 109, no. 4, pp. 1283-1288, 1995.

[76] M. M. Hoeper, M. J. Krowka, and C. P. Strassburg, "Portopulmonary hypertension and hepatopulmonary syndrome," The Lancet, vol. 363, no. 9419, pp. 1461-1468, 2004.

[77] R. Budhiraja and P. M. Hassoun, "Portopulmonary hypertension: a tale of two circulations," Chest, vol. 123, no. 2, pp. 562576, 2003.

[78] M. S. Mandell and B. M. Groves, "Pulmonary hypertension in chronic liver disease," Clinics in Chest Medicine, vol. 17, no. 1, pp. 17-33, 1996.

[79] R. J. Panos and S. K. Baker, "Mediators, cytokines, and growth factors in liver-lung interactions," Clinics in Chest Medicine, vol. 17, no. 1, pp. 151-170, 1996.

[80] B. D. Robalino and D. S. Moodie, "Association between primary pulmonary hypertension and portal hypertension: analysis of its pathophysiology and clinical, laboratory and hemodynamic manifestations," Journal of the American College of Cardiology, vol. 17, no. 2, pp. 492-498, 1991.

[81] A. Cardenas, T. Kelleher, and S. Chopra, "Review article: hepatic hydrothorax," Alimentary Pharmacology and Therapeutics, vol. 20, no. 3, pp. 271-279, 2004.

[82] F. L. Lieberman, R. Hidemura, R. L. Peters, and T. B. Reynolds, "Pathogenesis and treatment of hydrothorax complicating cirrhosis with ascites.", Annals of Internal Medicine, vol. 64, no. 2, pp. 341-351, 1966.

[83] J. Castellote, J. Gornals, C. Lopez, and X. Xiol, "Acute tension hydrothorax: a life-threatening complication of cirrhosis," Journal of Clinical Gastroenterology, vol. 34, no. 5, pp. 588-589, 2002. 
[84] X. Xiol, J. M. Castellví, J. Guardiola et al., "Spontaneous bacterial empyema in cirrhotic patients: a prospective study," Hepatology, vol. 23, no. 4, pp. 719-723, 1996.

[85] J. H. Zavecz, O. Bueno, R. E. Maloney, J. M. O’Donnell, S. C. Roerig, and H. D. Battarbee, "Cardiac excitation-contraction coupling in the portal hypertensive rat," American Journal of Physiology-Gastrointestinal and Liver Physiology, vol. 279, no. 1, pp. G28-G39, 2000.

[86] M. Levy and M. J. Wexler, "Renal sodium retention and ascites formation in dogs with experimental cirrhosis but without portal hypertension or increased splanchnic vascular capacity," Journal of Laboratory and Clinical Medicine, vol. 91, no. 3, pp. 520-536, 1978.

[87] M. Bolognesi, D. Sacerdoti, A. Piva et al., "Carbon monoxidemediated activation of large-conductance calcium-activated potassium channels contributes to mesenteric vasodilatation in cirrhotic rats," Journal of Pharmacology and Experimental Therapeutics, vol. 321, no. 1, pp. 187-194, 2007.

[88] R. Sarkar, E. G. Meinberg, J. C. Stanley, R. D. Gordon, and R. C. Webb, "Nitric oxide reversibly inhibits the migration of cultured vascular smooth muscle cells," Circulation Research, vol. 78, no. 2, pp. 225-230, 1996.

[89] D. Fernandez-Munoz, C. Caramelo, and J. C. Santos, "Systemic and splanchnic hemodynamic disturbances in conscious rats with experimental liver cirrhosis without ascites," American Journal of Physiology-Gastrointestinal and Liver Physiology, vol. 12, no. 3, pp. G316-G320, 1985.

[90] W. H. Abelmann and B. H. Lorell, "The challenge of cardiomyopathy," Journal of the American College of Cardiology, vol. 13, no. 6, pp. 1219-1239, 1989.

[91] S. W. van der Merwe, J. B. Van Den Bogaerde, C. Goosen et al., "Hepatic osteodystrophy in rats results mainly from portasystemic shunting," Gut, vol. 52, no. 4, pp. 580-585, 2003.

[92] F. J. Gallego-Rojo, J. L. Gonzalez-Calvin, M. Muñoz-Torres, J. L. Mundi, R. Fernandez-Perez, and D. Rodrigo-Moreno, "Bone mineral density, serum insulin-like growth factor I, and bone turnover markers in viral cirrhosis," Hepatology, vol. 28, no. 3, pp. 695-699, 1998.

[93] S. Cockayne, J. Adamson, S. Lanham-New, M. J. Shearer, S. Gilbody, and D. J. Torgerson, "Vitamin K and the prevention of fractures: systematic review and meta-analysis of randomized controlled trials," Archives of Internal Medicine, vol. 166, no. 12, pp. 1256-1261, 2006.

[94] J. E. Compston, "Hepatic osteodystrophy: vitamin D metabolism in patients with liver disease," Gut, vol. 27, no. 9, pp. 1073-1090, 1986.

[95] M. Peck-Radosavljevic, "Hypersplenism," European Journal of Gastroenterology and Hepatology, vol. 13, no. 4, pp. 317-323, 2001.

[96] E. Moschcowitz, "The pathogenesis of splenomegaly in hypertension of the portal," Medicine, vol. 27, no. 2, pp. 187-221, 1948. 


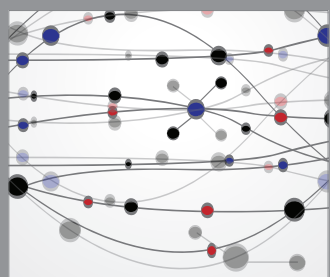

The Scientific World Journal
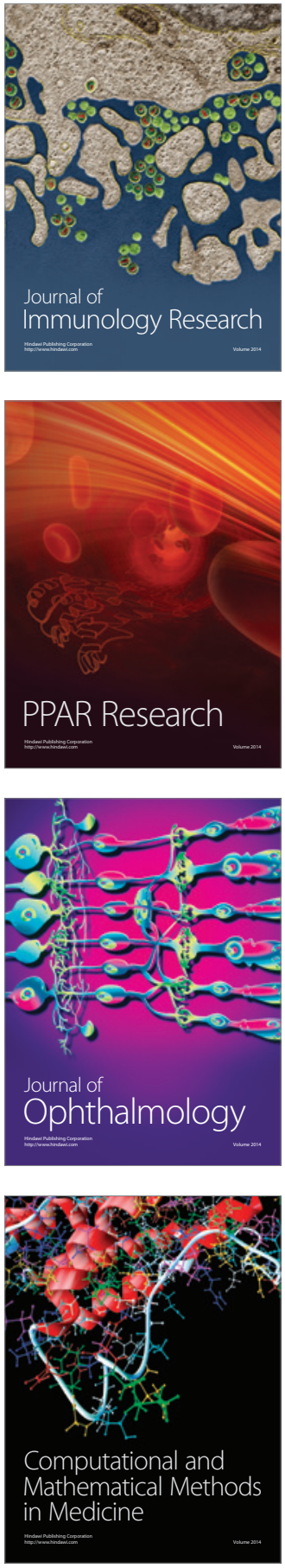

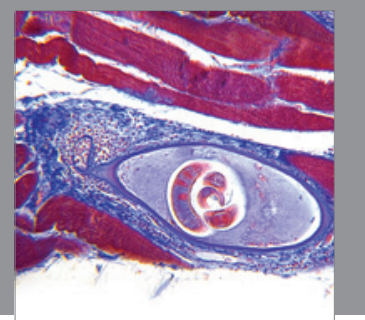

Gastroenterology

Research and Practice
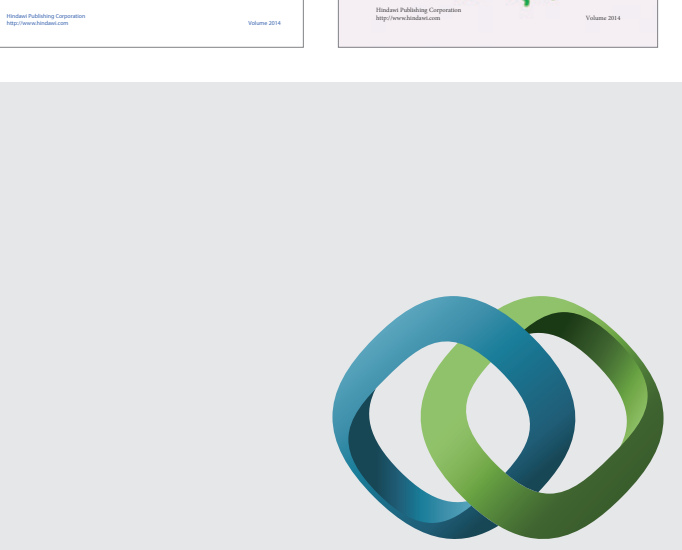

\section{Hindawi}

Submit your manuscripts at

http://www.hindawi.com
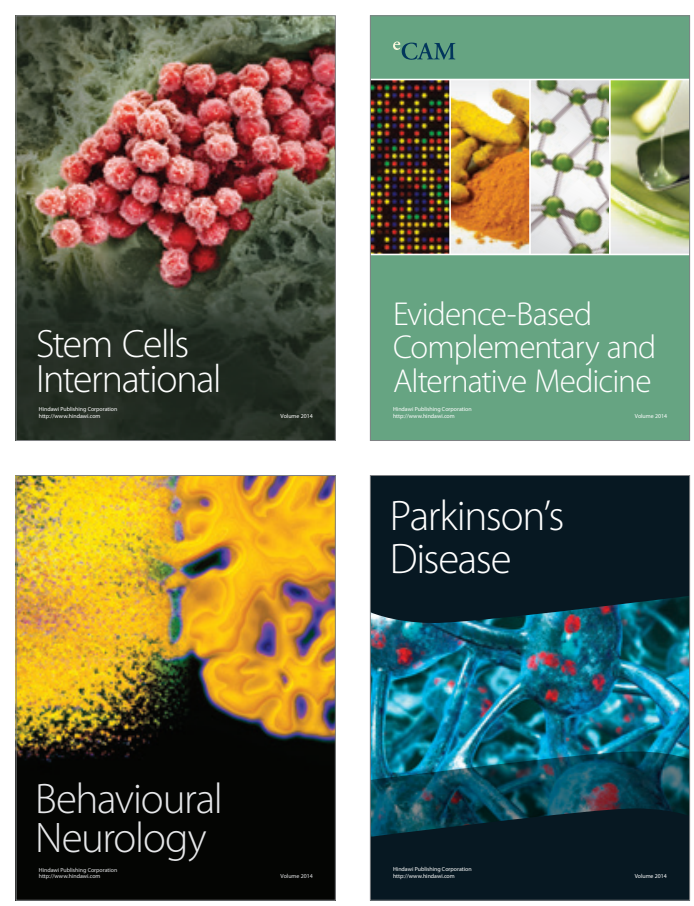

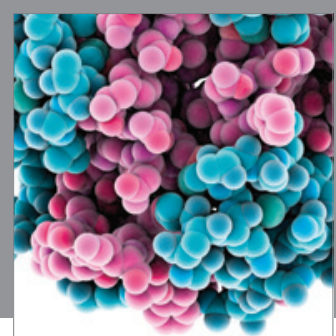

Journal of
Diabetes Research

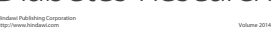

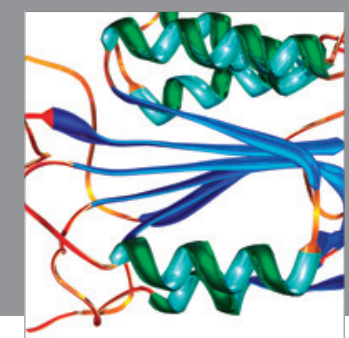

Disease Markers
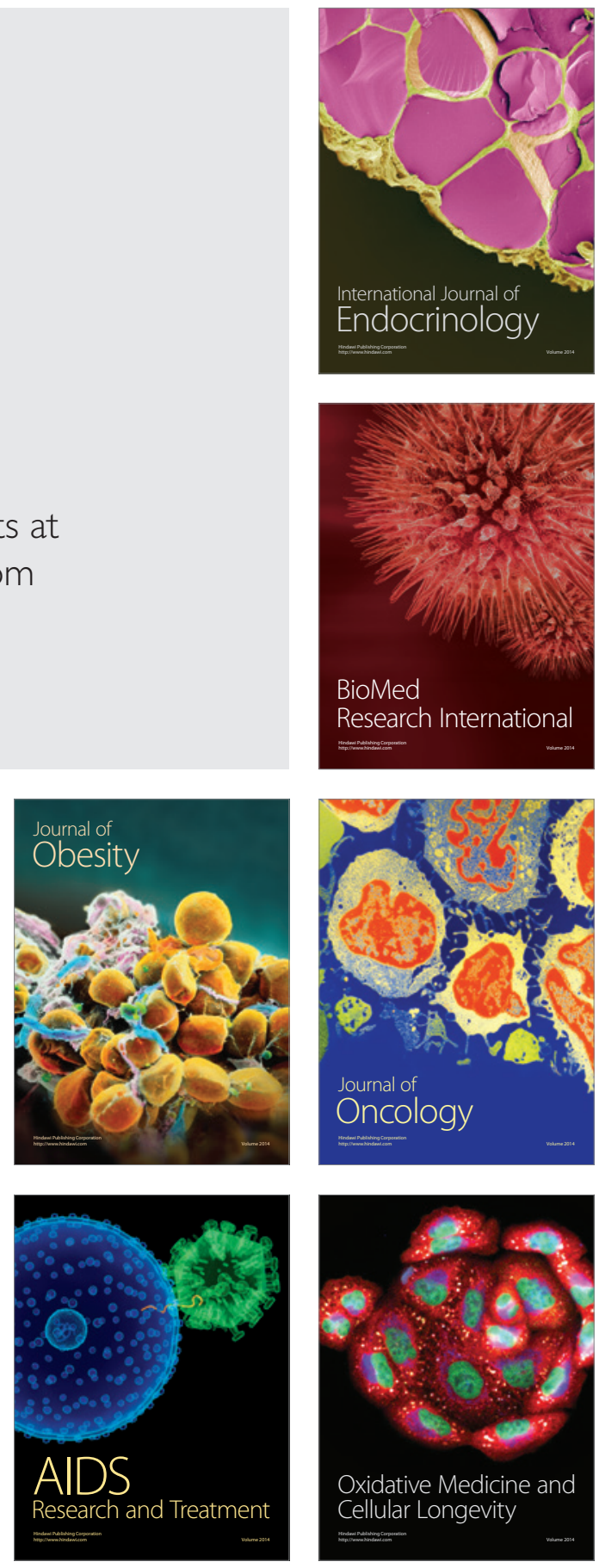